\title{
Prevalencia de leptospirosis en roedores sinantrópicos de la Ciudad de Corrientes, Argentina. Período mayo 2005-junio 2008
}

\author{
Marder, G. ${ }^{1}$; Ruiz, R.M.'; Bottinelli, O.R.'; Peiretti, H.A.'; Zorzo, L. '; Merino, D.E. ${ }^{3}$; \\ Czernik, G.E. ${ }^{3}$
}

${ }^{1}$ Cátedra de Salud Pública, ${ }^{2}$ Cátedra de Bromatología e Higiene Alimentaria, Facultad de Ciencias Veterinarias, UNNE, Sargento Cabral 2139, Corrientes (3400), Argentina, Tel/Fax 03783-425753. ${ }^{3}$ Facultad Medicina UNNE. E-mail: patcom@vet.unne.edu.ar.

\begin{abstract}
Resumen
Marder, G.; Ruiz, R.M.; Bottinelli, O.R.; Peiretti, H.A.; Zorzo, L.; Merino, D.E.; Czernik, G.E.: Prevalencia de leptospirosis en roedores sinantrópicos de la Ciudad de Corrientes, Argentina. Período mayo 2005-junio 2008. Rev. vet. 19: 2, 150-153, 2008. La leptospirosis es una zoonosis causada por bacterias del género Leptospira sp., las cuales regularmente provocan brotes de la enfermedad en Argentina, donde el conocimiento de su epidemiología es incompleto. Los roedores (ratas y ratones sinantrópicos y silvestres) son los principales reservorios de leptospirosis en nuestro medio. El objetivo del estudio fue investigar la presencia de Leptospira sp. en roedores de la Ciudad de Corrientes, Argentina, así como la especie, sexo y edad de los ejemplares positivos a leptospirosis. Fueron capturados 101 especimenes, cuyo tejido renal fue utilizado para demostrar la presencia de Leptospira sp. mediante microscopio de campo oscuro a partir de cultivos de 15 días hasta un máximo de 6 meses. La tasa de positividad detectada fue de $58,4 \%$, con una alta proporción de animales machos de la especie Rattus rattus. Solamente pudo capturarse un ejemplar de Mus musculus, que resultó infectado. Se concluye que la alta prevalencia de leptospirosis en roedores del área en estudio constituye un alarmante factor de riesgo de infección en animales domésticos y seres humanos.
\end{abstract}

Palabras clave: rata, leptospirosis, epidemiología, Corrientes, Argentina.

\begin{abstract}
Marder, G.; Ruiz, R.M.; Bottinelli, O.R.; Peiretti, H.A.; Zorzo, L.; Merino, D.E.; Czernik, G.E.: Prevalence of leptospirosis in sinantropic rodents from Corrientes City, Argentina. Period May 2005-June 2008. Rev. vet. 19: 2, 150-153, 2008. Leptospirosis is a zoonotic disease caused by Leptospira sp., affecting both animals and human beings. Outbreaks of leptospirosis occur frequently in Argentina, but little is known about its epidemiology. Reservoirs of leptospirosis in the environment are mainly rodents (mice, rats, and wild mice), that live in the vicinity of human settlements. Aim of this study was to investigate the prevalence of Leptospira sp. infection in rodents from Corrientes City, Argentina, as well as to gather information regarding species, sex and age of infected animals. One hundred and one rodents were captured from different areas of the city, classified and euthanized to collect kidney samples. To determine the presence of leptospiras, tissues were cultured during 15 days to a maximum of 6 months, and analyzed by means of dark-filed microscope. From the total of the tissue samples, $58 \%$ of the animals were positive to leptospira infection, with a high proportion of males of Rattus rattus species. We consider that the high prevalence of leptospirosis in rodents of the areas under study is a risk factor for both human beings and domestic animals, and control of these populations has to be taken into account.
\end{abstract}

Key words: rat, leptospirosis, epidemiology, Corrientes, Argentina.

\section{INTRODUCCIÓN}

La leptospirosis es considerada una de las zoonosis más diseminada y sub-diagnosticada en el mundo ${ }^{8}$. La Organización Mundial de la Salud (OMS) remarca

Recibido: 1 julio 2008 / Aceptado: 9 setiembre 2008 su importante prevalencia en ecosistemas influenciados por factores apropiados para la sobrevivencia de Leptospira sp. ${ }^{12}$, representando un problema de salud pública en los países subdesarrollados o en vías de desarrollo ${ }^{5,9}$. Es una enfermedad aguda y generalizada caracterizada por una vasculitis infecciosa que provoca innumerables alteraciones en órganos nobles como pul- 
mones, hígado y riñones ${ }^{3,14}$. Los síntomas clásicos son fiebre, ictericia, nefropatía, meningitis aséptica, neumonía atípica, hemorragias cutáneo-mucosas y con menor frecuencia se presenta insuficiencia renal grave por necrosis tubular y hemorragia visceral ${ }^{13}$.

Si bien el hombre puede contraer la infección en labores riesgosas, investigaciones realizadas en países sudamericanos demostraron que el aumento de la prevalencia de esta zoonosis está fuertemente relacionada con el empeoramiento de las condiciones de vida y trabajo de las poblaciones ${ }^{2}$. Desde el punto de vista de la salud pública deben controlarse los reservorios y fuentes de infección que posibiliten la transmisión de esta enfermedad ya que al ser sub-diagnosticada acarrea graves consecuencias cuando es confundida y tratada como otra patología. Así ocurrió en Nicaragua (1995), donde se registraron 40 defunciones a partir de 2000 pacientes, cuyo diagnóstico se confundió con el de dengue hemorrágico, debido a que ambas enfermedades comparten la sintomatología febril y hemorrágica ${ }^{15}$.

Existen numerosos animales que se comportan como reservorios de una gran heterogeneidad de leptospiras patógenas ${ }^{7,21}$. Los roedores juegan un destacado papel en el mantenimiento endémico de la infección en un área determinada. Son muchos los géneros y especies de roedores que actúan como reservorios, variando su presencia según zona geográfica. La rata o ratón de alcantarilla (Rattus norvergicus) y la rata negra o rata del techo (Rattus rattus) son considerados reservorios ecológicos de la leptospirosis, no desarrollando síntomas de esta zoonosis ${ }^{9}$. Otros roedores como Mus musculus, A. longipilis, O. longicaudatus, G. valdivianus y A. icrotus y A. olivaceus también actúan como reservorios de leptospiras ${ }^{16-20}$.

En Norteamérica y Europa se confeccionan mapas epidemiológicos de leptospirosis, con información sobre reservorios, nichos ecológicos y corredores endémicos. En cambio, en nuestro país y específicamente en la región nordeste, son escasos los trabajos realizados para determinar la ubicación geográfica de las áreas de riesgo ${ }^{11}$. La Provincia de Corrientes posee clima subtropical y otros factores que influyen para que el ecosistema sea adecuado para mantener viable la espiroqueta fuera del reservorio por más tiempo.

El objetivo del trabajo fue establecer la prevalencia de leptospirosis en reservorios roedores sinantrópicos de la Ciudad de Corrientes, estableciendo los géneros predominantes y su localización geográfica, para poder aplicar en un futuro medidas más eficientes de prevención y control.

\section{MATERIAL Y MÉTODOS}

El marco muestral fue determinado por el método de las proporciones, con nivel de confianza del 95\% y error admisible del $20 \%$, determinando una población suficiente de 96 roedores. Los especimenes fueron capturados con jaulas trampa de 0,30 ×0,14 ×0,14 m (distancia entre barrotes: $1,5 \mathrm{~cm}$ ). Como cebo se utilizó grasa bovina, semillas de zapallo, batata o choclo, alimentos que son muy apetecibles para los murinos.

Debido a la existencia de gran cantidad de reservorios de leptospirosis, como perros vagabundos y roedores, el área de elección para el estudio fue el casco céntrico de la Ciudad de Corrientes, superficie comprendida entre las cuatro avenidas principales. Veinte jaulas trampas se distribuyeron aleatoriamente en casas de familia y la presencia de roedores capturados fue verificada diariamente.

Los animales recolectados fueron identificados por sexo, especie, edad y lugar de procedencia. La necropsia se realizó bajo anestesia con hidrato de cloral al 1\%, acorde a las normas éticas en vigencia. Los riñones extraídos fueron flameados en mechero de Bunsen y triturados mediante el pasaje por una jeringa para ser sembrados en primera instancia en medio líquido de Korthoff. Luego de una hora de reposo, el sobrenadante se trasvasó a un medio semisólido de Korthoff y se incubó a $28^{\circ} \mathrm{C}$ durante 48 horas. Ulteriormente los cultivos fueron llevados a temperatura ambiente al abrigo de la luz. La lectura se realizó en microscopio de campo oscuro con objetivo 20 a partir de los 15 días de la siembra, repitiendo las lecturas cada quince días hasta un máximo de seis meses.

Estadísticamente se calcularon medidas descriptivas de tendencia central y dispersión. La significación de las diferencias entre grupos se indagó por la prueba de Chi cuadrado $\left(\chi^{2}\right)$, realizada con el auxilio del sistema EPIDAT 3.0 (OPS-OMS).

\section{RESULTADOS}

Fueron capturados y procesados 101 roedores. Un solo animal perteneció a la especie $M$. musculus y se trató de un macho que resultó positivo a leptospirosis. Los otros 100 especímenes fueron $R$. rattus (Figura 1), de los cuales 72 fueron machos (45 de ellos positivos) y 28 fueron hembras (13 positivas), como indica la Tabla 1 . La prevalencia a leptospirosis en $R$. rattus fue del $58 \%$ y la prevalencia en el total de roedores fue de $58,4 \%$.

Los ejemplares positivos de $R$. rattus sexo hembra fueron divididos en seis grupos etáreos. La distribución fue la siguiente: grupo de $1-3$ meses ( $n=5$ positivos), 4-6 meses $(n=3), 7-9$ meses $(n=3), 10-12$ meses $(n=0)$, $13-15$ meses $(n=0)$ y 18 a 24 meses $(n=2)$. Los machos infectados se distribuyeron así: grupo de 1 a 3 meses $(n=10$ positivos), 4 a 6 meses $(n=6), 7$ a 9 meses $(n=8)$, 10 a 12 meses $(n=12), 16$ a 18 meses $(n=6)$ y 19 a 24 meses $(n=3)$. La prueba del Chi cuadrado entre machos positivos $\mathrm{y}$ hembras positivas fue $\mathrm{p}>0,14$ indicando que no hubo diferencias significativas entre sexos.

Las edades de los roedores capturados oscilaron entre 1 y 24 meses, siendo la mediana de 6 meses. En el análisis estadístico se hallo un promedio de 6,42 meses para las hembras y de 8,4 meses para los machos. El desvío estándar fue de 4,35 meses para las hembras y 5,87 para los machos. Del análisis de la edad de los es- 
pecimenes macho positivos, surge un rango de 1 a 18 meses, con una media de 9,3 meses y un desvío estándar de 5,44 mientras que el rango para las hembras positivas fue de 2 a 18 meses con una media de 5,33 y un desvío estándar de 2,21. Estos datos permiten observar una dispersión ligeramente más amplia en las edades de la población de machos que en las de hembras, que se atribuye al azar, como indica la prueba de Chi cuadrado $(\mathrm{p}=0,17)$.

\section{DISCUSIÓN}

En la captura de roedores llamó la atención que solamente un animal de la especie $M$. musculus fuera atrapado, lo cual podría deberse a dos causas. En primer lugar, que las jaulas trampas utilizadas no hayan sido las más adecuadas para retener roedores de bajo peso como los ratones. Por otro lado, que la población de pequeños roedores haya sido escasa en el área de estudio, debido a la existencia de ratas de gran tamaño cuya presencia implica predominio de territorio; la verificación de esta hipótesis requeriría la realización de estudios poblacionales más profundos.

Si comparamos nuestros resultados con los hallados por otros investigadores en la Ciudad de Buenos Aires ${ }^{1}$ podemos corroborar el predominio de diferentes especies según área geográfica, ya que en esta última provincia predominó la especie Rattus norvegicus con una prevalencia de $45,8 \%$. La circunstancia que el único ratón capturado resultara positivo a leptospirosis, indica que probablemente las colonias de esta especie constituyan reservorios de leptospiras en el área relevada.

Estudios realizados en Colombia en áreas de producción de porcinos, utilizaron el mismo sistema de jaulas trampas, sin obtener diferencias entre porcentaje de machos y hembras capturados ${ }^{10}$. Nuestros resultados indican una alta prevalencia de machos capturados sobre la tasa de hembras capturadas, quizás debido a que el comportamiento exploratorio de los machos sea más activo que el de las hembras, lo cual implica una mayor
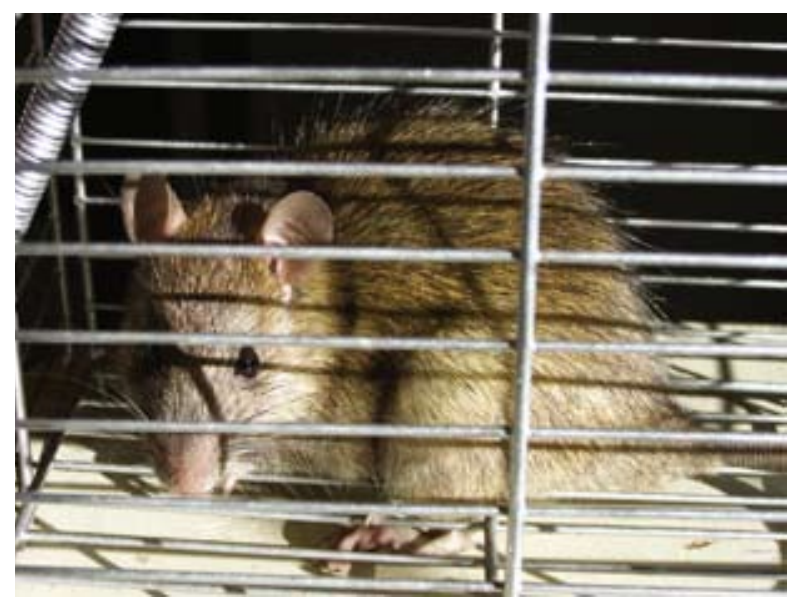

Figura 1. $R$. rattus en jaula de captura. probabilidad de caer en las trampas. Además, dentro de las colonias, los machos tienen acceso prioritario a la alimentación y a defender la unidad territorial, lo que los hace aún mas susceptibles de ser capturados ${ }^{4}$. Sin embargo, no hubo diferencias significativas en la positividad a leptospiras entre machos y hembras, por lo cual debe considerarse que ambos sexos se comportan de igual manera como reservorios de esta enfermedad.

Las especies de roedores consideradas de riesgo varían de acuerdo a las regiones geográficas, que a su vez condicionan las distintas formas de transmisión ${ }^{6,10}$. Cada especie de roedor tiene una madriguera y formas de desplazamiento características. $R$. rattus se traslada por lugares altos donde normalmente establece sus escondrijos, sin embargo Rattus norvegicus habitualmente lo hace a nivel del suelo y es ahí donde posee sus guaridas.

En futuras investigaciones se impone la determinación del serovar de Leptospira sp., técnica que requiere el uso de anticuerpos monoclonales, cuyo costo superó las previsiones presupuestarias del presente trabajo.

Se concluye que la alta prevalencia de animales positivos denota la existencia de una importante fuente de infección en el área urbana central de la Ciudad de Corrientes. Estas características implican un serio problema de salud pública, por un lado debido a la presencia de los reservorios de leptospirosis conviviendo con la comunidad humana y por el otro a la falta de conocimiento de nuestra población sobre el tema en cuestión con la alta probabilidad de contraer la enfermedad. Estos resultados alertan sobre la necesidad de aplicar programas de promoción de la salud y control de roedores.

\section{REFERENCIAS}

1. Arango J, Cittadino E, Agostini A, Mazzonelli D, Gleyre D, Alvarez C, Colusi M, Koval A, Cabrera A, Kravetz F. 2001. Prevalencia de leptospiras en Rattus rattus y Rattus norvegicus en el Gran Buenos Aires, Argentina. Ecología Austral 11: 25-30.

2. Carneiro M, Giacomini L, Costa MJ. 2004. Leptospirosis asociada a la exposición ocupacional: Estudio clínico y epidemiológico. Rev Chil Infect 21: 339-344.

3. Costa E, Costa Y, López A, Sacramento E, Bina J. 2001. Formas graves de leptospirose: aspectos clínicos, demográficos e ambientais. Rev Soc Bras Med Trop 34: 261267.

4. Coto H. 2007. Actualización en biología y control de ratas sinantrópicas, Ed. Gestalt Group, Buenos Aires, p. 205257.

5. Dabanch PJ. 2003. Zoonosis. Rev Chil Infectol 20: 47-51. 
6. De Serres G, Levesque B, Higgins R, Major M, Laliberté D, Boulianne N. 1995. Need for vaccination of sewer workers against leptospirosis and hepatitis A. Occup Environ Med 52: 505-507.

7. Faine S. 1994. Leptospira and leptospirosis, CRC Press, London, $353 \mathrm{p}$.

8. Favero AC, Pinheiro SR, Vasconcellos SA, Morais ZM, Ferreira F, Neto JS. 2002. Sorovares de leptospiras predominantes em exames sorológicos de bubalinos, ovinos, caprinos, eqüinos, suínos e cães de diversos estados brasileiros. Ciência Rural 32: 613-619.

9. Fundação Nacional de Saúde (FUNASA). 2003. Guia de vigilância epidemiológico, Ed. Funasa, Brasília, 119 p.

10. Giraldo DG, Orrego U, Betancurth AM. 2002. Los roedores como reservorios de leptospiras en planteles porcinos de la zona central cafetera de Colombia. Arch Med Vet 34: 1-2.

11. Martín UO, Sensevy A, Colombo J, Tramontin V. 2002. Leptospirosis en la Provincia de Santa Fe. Descripcion epidemiológica, clínica y socioeconómica. Medicina (Buenos Aires) 62: 136-140.

12. OMS. 2007. Zoonotic Diseases. http://www.who.int/cds/ vph/profile.html.

13. Seijo A, Coto H, San Juan J, Videla J, Deodato B, Cernigoi B, Messina O, Collia O, Bassadoni D, Schtirbu R, Olenchuk A, Mazzonelli G, Parma A. 2002. Distres respiratorio debido a hemorragia pulmonar por leptospirosis. Medicina (Buenos Aires) 62: 136-140.
14. Vinetz JM. 2001. Leptospirosis. Curr Opin Infect Dis 14: 527-538.

15. Zaki SR, Shieh WJ. 1996. Leptospirosis associated with outbreak of acute febrile illness and pulmonary hemorrhage. Lancet 347: 535-536.

16. Zamora J, Murua R. 1976. Infecciones por leptospira en roedores silvestres. Comunicación preliminar. Arch Med Vet 8: $120-121$.

17. Zamora J, Riedemann S, Cabezas X. 1994. Relación entre algunos aspectos ambientales y la infección por $L$. interrogans en roedores de la Provincia de Valdivia. Medio Ambiente 12: 3-8.

18. Zamora J, Riedemann S, Cabezas X. 1995. Leptospirosis de los roedores silvestres en el área rural de Valdivia. Pesquisa de $L$. interrogans mediante inmunofluorescencia e inmunoperoxidasa. Arch Med Vet 27: 115-118.

19. Zamora J, Riedemann S, Cabezas X, Vega S. 1995. Comparación de cuatro métodos para el diagnóstico de leptospirosis en roedores silvestres en el área rural de Valdivia, Chile. Rev Lat Microbiol 37: 267-272.

20. Zamora J. 1998. Riesgo epidemiológico de la fauna silvestre en problemas de salud. Anales X Congreso de Medicina Veterinaria, Valdivia (Chile), p. 127-151.

21. Zamora J, Riedemann S. 1999. Animales silvestres como reservorios de leptospirosis en Chile. Una revisión de los estudios efectuados en el país. Arch Med Vet 31: 151-156. 